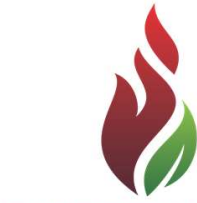

SUSTENERE

Publishing Corporation

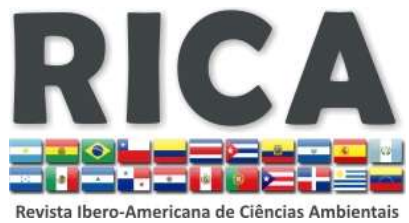

Journals Homepage:

www.sustenere.co/journals

\section{ANÁLISE ESPAÇO-TEMPORAL DE PARÂMETROS DE QUALIDADE DA ÁGUA NO RIO PIRACICABA, MINAS GERAIS, BRASIL}

\section{RESUMO}

O presente trabalho buscou verificar a contribuição física, química e biológica do reservatório da Usina Hidrelétrica de Sá Carvalho, para o Rio Piracicaba, Bacia Hidrográfica do Rio Doce, Minas Gerais. Realizaram-se coletas quadrimestrais da água superficial (bruta), nos períodos de seca e chuva, entre novembro/2006 até julho/2012, em quatro pontos de coletados localizados em Nova Era (P1), Timóteo (P2), Coronel Fabriciano (P3) e Ipatinga (P4) nas proximidades do seu deságüe no Rio Doce. As variáveis limnológicas foram coletadas e avaliadas de acordo com CETESB (2006) e APHA (2005), enquanto os dados pertinentes ao reservatório foram obtidos através dos relatórios produzidos pela CEMIG (2012). Quanto ao reservatório constatou-se que em sua área da captação ocorrem atividades agropecuárias e extrativismo florestal com repercussões, tais como, a desertificação que promove alterações climáticas influenciando a concentração das substâncias químicas no corpo hídrico. Em todas as localidades desse estudo apurou-se IQA regular. Os piores resultados foram detectados na estação seca explicitando relação com a elevação da turbidez indicando melhor correlação em P4 sendo constatado que a redução da precipitação pluviométrica se constituiu em impeditivo para autodepuração sendo identificadas condições de intenso assoreamento também à jusante da UHE - Sá Carvalho. Constatou-se que a geração de energia elétrica não é principal responsável pela degradação do manancial perdendo para a siderurgia, mineração, esgoto sanitário e exploração florestal. Entende-se que deve ser intensificado o programa de preservação das áreas degradadas e educação ambiental visando o desenvolvimento sustentável da região de estudo.

PALAVRAS-CHAVES: Rio Piracicaba; Hidrelétrica; Qualidade da Água; Eutrofização.

\section{SPATIO-TEMPORAL ANALYSIS OF WATER QUALITY PARAMETERS IN RIO PIRACICABA, MINAS GERAIS, BRAZIL}

\section{ABSTRACT}

This study aimed to verify the physical contribution, chemical and biological Hydropower Plant Sá Carvalho reservoir for the Piracicaba River Basin Rio Doce, Minas Gerais. There were quarterly collections of surface water (floor), in periods of drought and rain, between November / 2006 to July / 2012 in four points collected located in Nova Era (P1), Timóteo(P2), Coronel Fabriciano (P3 ) and Ipatinga (P4) near their outflow in Rio Doce. Limnological parameters were recorded and evaluated according to CETESB (2006) and APHA (2005), while the relevant data to the reservoir were obtained from the reports produced by Cemig (2012). As the reservoir was found that in its catchment area occur agricultural and forest extraction activities with repercussions such as desertification promoting climate change influencing the concentration of chemicals in the water body. In all localities of the study it was found regular IQA. The worst results were detected in the dry season explicit relationship with the increase in turbidity indicating a stronger correlation P4 and revealed that the reduction of rainfall was incurred deterrent for self-purification being identified heavy silting conditions also downstream from HPP - Sá Carvalho. It was found that the power generation is not primarily responsible for the source of degradation losing to the steel, mining, sewage and logging. It is understood that should be intensified preservation program of degraded areas and environmental education for sustainable development of the study area.

KEYWORDS: Rio Piracicaba; Hydroelectric; Water Quality; Eutrophication.
Revista Ibero-Americana de

Ciências Ambientais, Aquidabã, v.6, n.2, Jun, Jul, Ago, Set, Out, Nov 2015.

ISSN 2179-6858

\section{SECTION: Articles} TOPIC: Recursos Hídricos

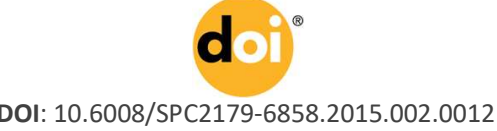

Marluce Teixeira Andrade Queiroz

Centro Universitário do Leste de Minas Gerais, Brasil http://lattes.cnpq.br/9640840965900909 marluce.queiroz@bol.com.br

Millor Godoy Sabará

Universidade do Estado de Minas Gerais, Brasil http://lattes.cnpq.br/1451530668281758 mgsabar@uol.com.br

Carolina Andrade Queiroz

Universidade Federal de Viçosa, Brasil http://lattes.cnpq.br/0179392720884169 carolanq@yahoo.com.br

Mônica Maria Diniz Leão

Universidade do Estado de Minas Gerais, Brasil http://lattes.cnpq.br/6775138764763493 monica@ufmg.com.br

Camila Costa de Amorim Universidade Federal de Minas Gerais, Brasil http://lattes.cnpq.br/9940811381309673 camila@ufmg.com.br

Received: 10/02/2015

Approved: 14/10/2015

Reviewed anonymously in the process of blind peer.

\section{Referencing this:}

QUEIROZ, M. T. A.; SABARÁ, M. G.; QUEIZOZ, C. A.; LEÃO, M. M. D.; AMORIM, C. C.. Análise espaçotemporal de parâmetros de qualidade da água no Rio Piracicaba, Minas Gerais, Brasil. Revista IberoAmericana de Ciências Ambientais, Aquidabã, v.6, n.2, p.170-182, 2015. DOI:

http://dx.doi.org/10.6008/SPC21796858.2015 .002 .0012 


\section{INTRODUÇÃO}

A matriz energética do Brasil se apoia em fontes não renováveis (petróleo, carvão e gás natural) e renováveis (eólica, solar, biomassa e nuclear). Destaca-se a relevância do seu potencial hidráulico $(30 \%)$ usado principalmente na produção de energia em hidrelétricas que abastecem $90 \%$ do consumo de eletricidade ao nível nacional (MMA, 2014). Em relação às hidrelétricas, os ecossistemas se submetem há grande diversidade de riscos agravado pelos reflexos negativos a jusante e montante do seu entorno que se perenizam ao longo do tempo (PIZELLA et al., 2012). Pode-se afirmar que a biodiversidade é afetada principalmente pelo ciclo migratório de diversas espécies em função das barreiras físicas e modificações na temperatura da água e concentração de poluentes capaz de contribuir para a proliferação de patologias na fauna aquática (SILVA et al., 2013). Além disso, muitas vezes, ocorre a inclusão de espécies exóticas que podem entrar em competição com as nativas sujeitando, muitas vezes, as últimas à extinção (FRANKLIN et al., 2014).

Em relação aos recursos hídricos, outro grave problema se refere à redução do teor de Oxigênio Dissolvido (OD) notadamente na estação seca (sem chuvas e ventos). A grande estabilidade climática redunda em pouca movimentação da água do reservatório diminuindo sua aeração, afetando assim a qualidade da água à jusante da barragem (NOBREGA et al., 2013). Nesse contexto, a mensuração do Índice de Qualidade da Água (IQA) assume especial importância na descrição das condições aquáticas e possibilitando a proposição de medidas mitigadoras auxiliando o planejamento ambiental no uso sustentável em bacias hidrográficas (RODRIGUES et al., 2012). Sendo assim, esse estudo direcionou-se para Bacia Hidrográfica do Rio Piracicaba (BHRP), pertencente à Bacia Hidrográfica do Rio Doce (BRDD), que exibe conjunto expressivo de atividades econômicas e domiciliares, contando com a contribuição energética da Usina Hidrelétrica Sá Carvalho (UHE Sá Carvalho), Antônio Dias, Minas Gerais, na sustentação do desenvolvimento regional (PEREIRA et al., 2011).

Nesse estudo, priorizou-se analisar a influência do barramento na qualidade da água a jusante do reservatório da UHE - Sá Carvalho, entre julho/2010 e julho/2012, abarcando aspectos pertinentes aos impactos relacionados às variações do índice de precipitação pluviométrico (estação seca e chuvosa). Em atendimento à proposta foram realizados ensaios físico-químicos em amostras da água superficial e os resultados foram utilizados para a construção do Índice de Qualidade da Água (IQA) em quatro pontos de coleta, localizados em Nova Era $\left(\mathrm{P}_{1}\right)$, Timóteo $\left(\mathrm{P}_{2}\right)$, Coronel Fabriciano $\left(\mathrm{P}_{3}\right)$, Ipatinga $\left(\mathrm{P}_{4}\right)$, municípios no entorno do barramento. Além disso, alocouse na pequena área incremental, superfície de 216,13 $\mathrm{Km}^{2}$, a jusante da confluência do Rio Piracicaba com o Rio Doce, em seu principal curso d' água o Ribeirão Ipanema $\left(\mathrm{P}_{5}\right)$. $A$ análise dos resultados possibilitou o entendimento da dinâmica ambiental viabilizando a proposição de medidas mitigadoras devendo constituir-se em subsídio para o Programa de Planejamento e Gerenciamento da Bacia Hidrográfica (PGBH) naquela região. 


\section{REVISÃO TEÓRICA}

\section{Classes da Água}

Ao nível da realidade nacional a Resolução do Conselho Nacional do Meio Ambiente (CONAMA) $n^{\circ} 357 / 2005$ estabelece que as águas doces sejam aquelas com salinidade $\leq$ a $0,5 \%$ condição na qual se enquadra a BHRP - MG. Além disso, a referida legislação estabelece classes de qualidade para água fluvial. Trata-se do conjunto das condições e padrões de qualidade de água necessários ao atendimento dos usos preponderantes, atuais ou futuros. Em observância a essas diretrizes são encontradas as seguintes classes que são apresentadas no Quadro 1.

Quadro 1: Classe da Água Fluvial e Destinação.

\begin{tabular}{|l|l|}
\hline Classe & Destinação \\
\hline Especial & $\begin{array}{l}\text { a) ao abastecimento para consumo humano, com desinfecção; } \\
\text { b) a preservação do equilíbrio natural das comunidades aquáticas; e, } \\
\text { c) a preservação dos ambientes aquáticos em unidades de conservação de proteção integral }\end{array}$ \\
\hline 1 & $\begin{array}{l}\text { a) ao abastecimento para consumo humano, apos tratamento simplificado; } \\
\text { b) a proteção das comunidades aquáticas; } \\
\text { c) a recreação de contato primário, tais como natação, esqui aquático e mergulho, conforme CONAMA no } \\
\text { 274/2000; } \\
\text { d) a irrigação de hortaliças que são consumidas cruas e de frutas que se desenvolvam rentes ao solo e que } \\
\text { sejam ingeridas cruas sem remoção de película; } \\
\text { e) e a proteção das comunidades aquáticas em Terras Indígenas. }\end{array}$ \\
\hline 2 & $\begin{array}{l}\text { a) ao abastecimento para consumo humano, apos tratamento convencional; } \\
\text { b) a proteção das comunidades aquáticas; } \\
\text { c) a recreação de contato primário, tais como natação, esqui aquático e mergulho, conforme Resolução } \\
\text { CONAMA nº 274/2000; } \\
\text { d) a irrigação de hortaliças, plantas frutíferas e de parques, jardins, campos de esporte e lazer, com os } \\
\text { quais o publico possa vir a ter contato direto; } \\
\text { e) e a aqüicultura e a atividade de pesca. }\end{array}$ \\
\hline 3 & $\begin{array}{l}\text { a) ao abastecimento para consumo humano, apos tratamento convencional ou avançado; } \\
\text { b) a irrigação de culturas arbóreas, cerealíferas e forrageiras; } \\
\text { c) a pesca amadora; } \\
\text { d) a recreação de contato secundário; } \\
\text { e) e a dessedentação de animais. }\end{array}$ \\
\hline 4 & $\begin{array}{l}\text { a) a navegação; } \\
\text { b) e a harmonia paisagística }\end{array}$ \\
\hline
\end{tabular}

Fonte: MMA, 2014.

\section{Índice de Qualidade das Águas}

O Índice de Qualidade das Águas (IQA) foi elaborado nos Estados Unidos da América (EUA) em 1970. No Brasil passou a ser utilizado a partir de 1975 pela Companhia Ambiental do Estado de São Paulo (CETESB). Nas décadas seguintes, outros Estados brasileiros adotaram o IQA, que hoje é o principal índice de qualidade da água bruta utilizado no país, tendo em vista o seu emprego para o abastecimento público, após tratamento. Os parâmetros utilizados no cálculo do IQA são em sua maioria indicadores de contaminação causada pelo lançamento de esgotos domésticos, portanto apresenta limitações relacionadas com o diagnóstico de vários indicadores importantes para o abastecimento público, tais como substâncias tóxicas (ex: metais pesados, 
pesticidas, compostos orgânicos), protozoários patogênicos e substâncias que interferem nas propriedades organolépticas da água (ANA, 2014).

O IQA é composto por nove parâmetros sendo, Turbidez, Temperatura da água, $\mathrm{pH}$, Oxigênio Dissolvido - OD, Demanda Bioquímica de Oxigênio - $\mathrm{DBO}_{5,20}$, Fósforo Total ( $\left.\mathrm{P}_{\text {Total }}\right)$, Nitrogênio Total ( $\left.N_{\text {Total }}\right)$, Coliformes Termotolerantes $(C T)$ e Resíduo Total $\left(R_{\text {total }}\right)$ ponderados através dos seus respectivos pesos (w) fixados em função da sua importância (Tabela 1) para conformação global do IQA de acordo com as diretrizes da Agência Nacional das Águas (ANA, 2014).

Tabela 1: Parâmetros de Qualidade da Água e respectivo peso.

\begin{tabular}{|l|l|}
\hline Parâmetro & Peso (w) \\
\hline Oxigênio Dissolvido (OD) & 0,17 \\
\hline Coliformes Termotolerantes (CT) & 0,15 \\
\hline Potencial Hidrogeniônico (pH) & 0,12 \\
\hline Demanda Bioquímica de Oxigênio (DBO5,20) & 0,10 \\
\hline Temperatura da Água (TÁgua) & 0,10 \\
\hline Nitrogênio Total (NTotal)) & 0,10 \\
\hline Fósforo Total (PTotall) & 0,10 \\
\hline Turbidez (TNTU) & 0.08 \\
\hline Resíduo Total (Rotal) & 0,08 \\
\hline
\end{tabular}

Em sequência deve ser calculado o produtório ponderado dos nove indicadores.

$$
\text { IQA }=\prod_{i=1}^{n} q_{i}{ }^{w}
$$

Expressão Matemática do Cálculo do IQA.

Sendo:

IQA = Índice de Qualidade das Águas. Um número entre 0 e 100;

qi = qualidade do i-ésimo parâmetro. Um número entre 0 e 100, obtido do respectivo gráfico de qualidade, em função de sua concentração ou medida (resultado da análise);

wi = peso correspondente ao i-ésimo parâmetro fixado em função da sua importância para a conformação global da qualidade, isto é, um número entre 0 e 1, de forma que:

$$
\sum_{i=1}^{n} w_{i}=1
$$

O IQA obtido viabiliza a classificação da qualidade da água em ótima, boa, regular, ruim ou péssima em decorrência do valor final obtido e conseqüente posicionamento na faixa de avaliação (Tabela 2).

Tabela 2: Faixa de IQA, Minas Gerais, Brasil.

\begin{tabular}{|l|l|}
\hline IQA & Qualidade da Água \\
\hline $91-100$ & Ótima \\
\hline $71-90$ & Boa \\
\hline $51-70$ & Razoável \\
\hline $26-50$ & Ruim \\
\hline $0-25$ & Péssima \\
\hline
\end{tabular}

Fonte: ANA, 2014 


\section{METODOLOGIA}

\section{Objeto de Estudo}

O Rio Piracicaba é considerado o principal formador do Rio Doce. A BHRD possui 83.400 $\mathrm{km}^{2}$, dos quais $86 \%$ em Minas Gerais e 14\% no Espírito Santo, sendo 222 municípios. No médio Rio Doce, que vai do Rio Piracicaba até o Rio Manhuaçú na cidade de Aimorés, é uma região com ampla diversidade econômica, prevalecendo às grandes indústrias no vale do aço e as atividades agropecuárias. É o trecho mais degradado e crítico da Bacia, existindo estudos apontando ser uma região em acelerado processo de desertificação devido à retirada das matas ciliares, grandes monoculturas de eucaliptos e pastagens, assim como a má utilização do solo e o rápido aparecimento das erosões, assoreando o leito do rio, lixos e esgotos industriais e domésticos. 0 corpo aquático originário do encontro do Rio Piranga com Rio do Carmo contribui para sustentação energética regional no Estado de Minas Gerais, Brasil. A UHE Sá Carvalho aproveita o potencial hidráulico do corpo aquático encontrando-se em operação desde 1951, possui potência instalada de $78 \mathrm{MW}$ e conta com quatro unidades geradoras. Apresenta duas barragens, a Antônio Dias com altura máxima de $14,8 \mathrm{~m}$ e a barragem Severo, com altura máxima de $14 \mathrm{~m}$, encontra-se na área de influência do Parque Estadual do Rio Doce (PERD) que apresenta remanescentes com vegetação nativa (CEMIG, 2014).

O município de Antônio Dias apresenta cidades limítrofes que são Ferros, a norte; Santa Maria de Itabira, a noroeste; Nova Era, a oeste; São Domingos do Prata, a sul; Jaguaraçu, a sudeste; Timóteo, a leste; e Coronel Fabriciano, a nordeste. Dentre essas, selecionou-se as localidades de Nova Era $\left(P_{1}\right)$, Timóteo $\left(P_{2}\right)$, Coronel Fabriciano $\left(P_{3}\right)$ para coleta de amostras de água superficial do Rio Piracicaba em regime quadrimestral. Além disso, alocou-se estação de amostragem em Ipatinga $\left(\mathrm{P}_{4}\right)$ próxima ao encontro do Rio Piracicaba com o Rio Doce. Os critérios observados foram à incidência de lançamentos de efluentes ao longo da drenagem, tributários na rede, possíveis fontes de poluição identificadas pela avaliação do uso e ocupação do solo e acessibilidade, sendo identificados com base nas suas coordenadas (Tabela 3 ).

Tabela 3: Pontos de Coleta no Rio Piracicaba.

\begin{tabular}{|l|l|l|l|}
\hline Ponto de Coleta & Coordenadas & $\begin{array}{l}\text { Distância em linha reta da UHE- Sá } \\
\text { Carvalho }(\mathrm{Km})^{\star}\end{array}$ & Uso do Solo à Montante \\
\hline $\mathrm{P}_{1}$ (Nova Era) & $\begin{array}{l}\text { S } 19^{\circ} 43^{\prime} 50^{\prime \prime} \\
\text { WO } 43^{\circ} \text { 00'51'” }\end{array}$ & 23,3 & $\begin{array}{l}\text { Agropecuária, exploração florestal, } \\
\text { extrativismo }\end{array}$ \\
\hline $\mathrm{P}_{2}$ (Timóteo) & $\begin{array}{l}\text { S } 19^{\circ} 32^{\prime} 40^{\prime \prime} \\
\text { WO } 42^{\circ} 37^{\prime} 40^{\prime \prime}\end{array}$ & 23,93 & $\begin{array}{l}\text { Siderurgia e intensa aglomeração } \\
\text { urbana }\end{array}$ \\
\hline $\mathrm{P}_{3}$ (C. Fabriciano) & $\begin{array}{l}\mathrm{S} 19^{\circ} 31^{\prime} 0^{\prime \prime} \\
\text { WO } 42^{\circ} 37^{\prime} 0^{\prime \prime}\end{array}$ & 28 & $\begin{array}{l}\text { Comércio, ocupação urbana em área } \\
\text { de risco }\end{array}$ \\
\hline $\mathrm{P}_{4}$ (Ipatinga) & $\begin{array}{l}\mathrm{S} 19^{\circ} 29^{\prime} 25^{\prime \prime} \\
\text { WO } 42^{\circ} 30^{\prime} 14^{\prime \prime}\end{array}$ & 39 & $\begin{array}{l}\text { Siderurgia e intensa aglomeração } \\
\text { urbana }\end{array}$ \\
\hline
\end{tabular}

Fonte: CEMIG, 2014. 


\section{Procedimentos de Coleta e Análise de Dados}

As amostras de água foram coletadas em recipientes de vidro de cor âmbar esterilizados. Imediatamente antes da coleta os recipientes foram ambientados três vezes com as águas em estudo. Em seguida, os frascos foram mergulhados no rio e virados lentamente, no sentido contra a corrente, até serem completamente preenchidos. Os procedimentos de coleta ocorreram com luvas para reduzir o risco de contaminação. As amostras foram acondicionadas em caixa de isopor, contendo blocos de gelo durante todo o período da campanha. As subamostras para cada análise ou conjunto destas foram separadas em frascos de polietileno, que, por sua vez, foram identificados e mantidos refrigerados à $4^{\circ} \mathrm{C}$ (APHA, 2005). Os parâmetros mensurados são mostrados na Tabela 4. As análises realizadas seguiram os procedimentos propostos pela American Public Health Association (APHA, 2005) e permitiram avaliar a qualidade de água do rio Piracicaba no período de estudo.

Tabela 4: Métodos de Análise dos Parâmetros Monitorados.

\begin{tabular}{|l|l|l|}
\hline Parâmetro & Método & APHA \\
\hline $\mathrm{CT}$ & Tubos múltiplos & $9221 \mathrm{E}$ \\
\hline $\mathrm{DBO}_{5}$ & incubação por 5 dias & $5210 \mathrm{~B}$ \\
\hline $\mathrm{P}_{\text {total }}$ & Vanadomobilídico & AT100 \\
\hline $\mathrm{N}_{\text {total }}$ & Kjeldhall & $4500 \mathrm{~N}^{-o r g ~ B}$ \\
\hline $\mathrm{OD}$ & Eletrométrico & $4500 \mathrm{H}^{+} \mathrm{B}$ \\
\hline $\mathrm{pH}$ & Eletrométrico & $4500 \mathrm{O}-\mathrm{G}$ \\
\hline $\mathrm{STD}$ & Gravimétrico & 2540 \\
\hline Temperatura & Termômetro de mercúrio & $2550 \mathrm{~B}$ \\
\hline Turbidez & Nefelometria & $2130 \mathrm{~B}$ \\
\hline
\end{tabular}

\section{RESULTADOS}

Esse estudo analisou impactos na qualidade da água em localidades próximas da UHE-Sá Carvalho instalada na BHRP. Destaca-se que o corpo d'água se submete aos efluentes derivados da agropecuária, silvicultura, exploração florestal, indústrias extrativas/transformação, produção/distribuição de eletricidade, gás e água, construção civil, comércio, reparação de veículos automotores, objetos pessoais e domésticos, alojamento e alimentação, transporte, armazenagem, comunicações, intermediação financeira, atividades imobiliárias, instituições públicas, dentre outros empreendimentos econômicos que repercutem no IQA da água. Ressaltase a inexistência de Estações de Tratamento de Esgoto (ETE) na grande maioria dos municípios percorridos pelo corpo d'água constituindo-se em fator agravante do risco ambiental e suas repercussões negativas.

A precipitação pluviométrica pode alterar significativamente a qualidade da água repercutindo em suas características físico-químicas e biológicas, em função do transporte de material alóctone para a BHRP, promovendo modificações pertinentes aos teores dos compostos químicos na coluna d'água. Nos meses que compreendem o verão, nota-se uma preponderância de instabilidade atmosférica, sendo observada chuvas causando em diversas oportunidades 
transtornos à população. No Gráfico 1 são apresentados os valores de precipitação acumulada no período entre novembro/2006 e julho/2010.

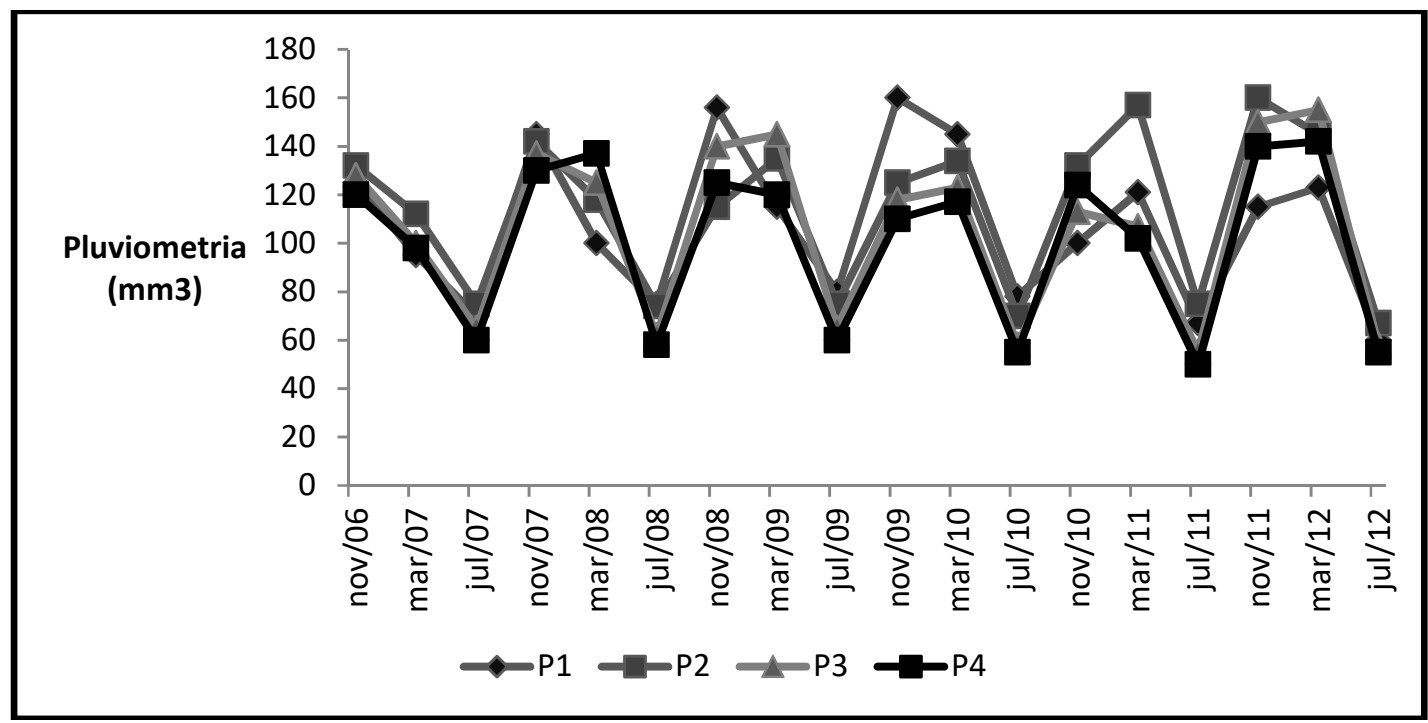

Gráfico 1: Precipitação Pluviométrica Acumulada em $\mathrm{P}_{1}, \mathrm{P}_{2}, \mathrm{P}_{3}$ e $\mathrm{P}_{4}$.

Fonte: Defesa Civil do Estado de Minas Gerais, 2014.

O IQA (Gráfico 2) refletiu ainda as alterações provenientes da urbanização (densidade demográfica, dinâmica da produção, o consumo de água e produção de esgoto). Destaca-se a interferência da industrialização relacionada com a exploração de minério de ferro, que apresenta impactos potenciais importantes sobre a qualidade de água, seja pela possibilidade de aumento de sólidos suspensos, seja pela alteração química da água nas lagoas de decantação utilizadas no beneficiamento do minério (ZIMMERMANN et al., 2008). Além disso, se verificou agravamento em função da redução pluviométrica na estação seca (Gráfico 1).

Com base nos resultados analíticos se apurou preponderância do IQA razoável (Gráfico 2) no rio Piracicaba, Minas Gerais em todos os pontos de coleta (Tabela 1), sendo os piores resultados identificados em $\mathrm{P}_{3}$ (Coronel Fabriciano) que se encontra a $28 \mathrm{~km}$ da UHE - Sá Carvalho (Tabela 1) perdendo em proximidade somente para $\mathrm{P}_{1}$ (Nova Era) e $\mathrm{P}_{2}$ (Timóteo). Vale destacar que se observou intenso assoreamento do Ribeirão Caladinho, situado à jusante de $\mathrm{P}_{3_{\overline{7}}}$ tributário da BHRP.

Além disso, na área rural à jusante e montante de $P_{3}$ foram detectadas fossas sépticas indicando exacerbação da degradação antrópica de rios e mananciais freáticos. Outro problema se relacionou com o risco potencial da erosão devido à supressão de vegetação e empobrecimento do solo após sua utilização como pasto e outros fins (PERESIN et al., 2014).

O comprometimento do IQA (Gráfico 2) na região de estudo se relacionou, principalmente, à elevação do teor de Coliforme Termo Tolerante (CT), Demanda Bioquímica de Oxigênio $\left(\mathrm{DBO}_{5}\right.$, 20), Fósforo Total ( $\left.P_{\text {Total }}\right)$, Nitrogênio Total $\left(N_{\text {Total }}\right)$, Resíduo Total $\left(R_{\text {Total }}\right)$ Turbidez $\left(T_{N T U}\right)$. A carga de CT preocupa, pois a sua presença em grandes números indica a possibilidade da existência de microorganismos patogênicos que são responsáveis pela transmissão de doenças de veiculação 
hídrica (ex: disenteria bacilar, febre tifóide, cólera) conforme informações do Ministério do Meio Ambiente (MMA, 2014).

Os resultados desse estudo extrapolaram o valor de 4.000 CT. $100 \mathrm{~mL}^{-}$em $780 \%, 757 \%$, 829\%, 924\% e 973\% das amostragens respectivamente em $\mathrm{P}_{1}, \mathrm{P}_{2}, \mathrm{P}_{3}$ e $\mathrm{P}_{4}$ contrariando as disposições das Resoluções do CONAMA n. 274/2000 e 357/2005 tornando-a imprópria para a recreação humana e dessedentação de animais. Vale destacar, atividades agropecuárias são importantes para economia regional. Segundo os dados censurados entre 2000 a 2012 ocorreu o crescimento no rebanho de bubalinos $(226,17 \%)$ e bovinos $(24,13 \%)$ na região. Dentre todas as indústrias, trata-se das principais responsáveis pela introdução de toneladas de excremento piorando a qualidade da água potável repercutindo negativamente na saúde do bioma (MACHADO et al., 2014).

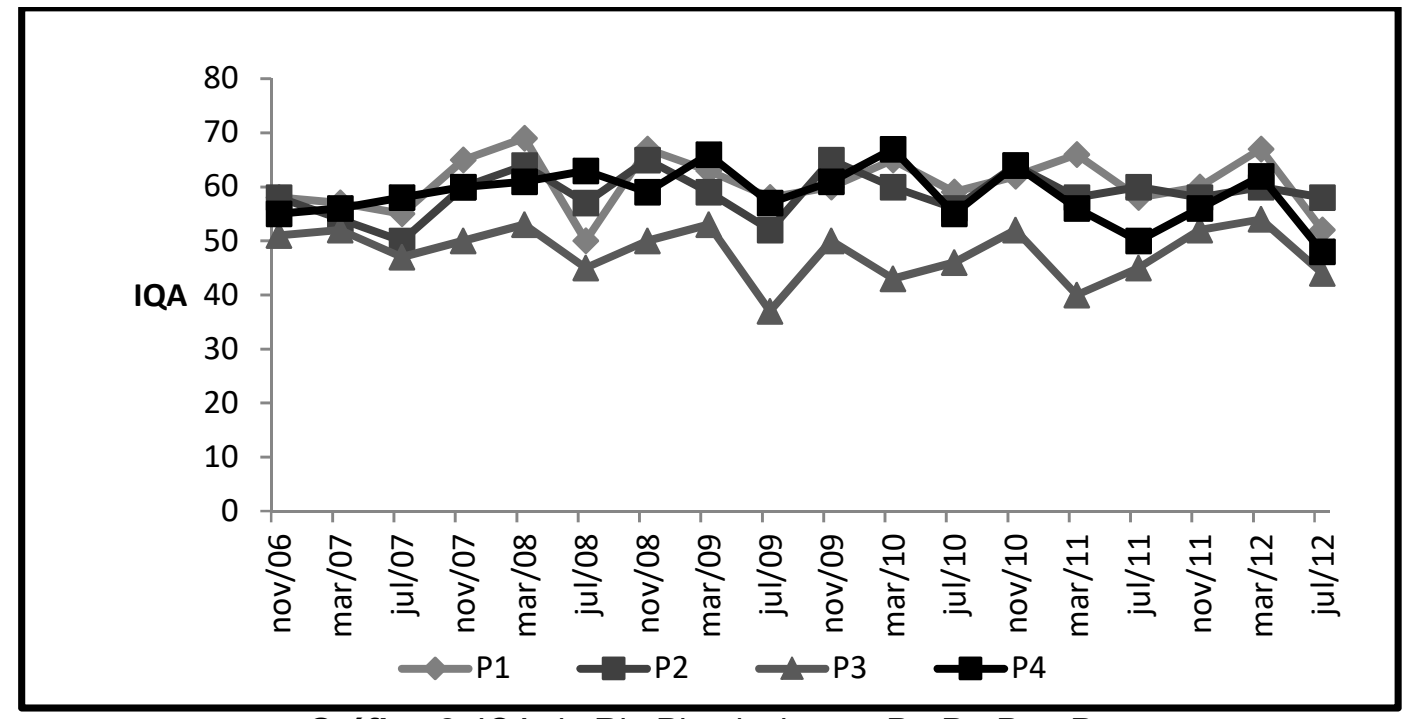

Gráfico 2: IQA do Rio Piracicaba em $\mathrm{P}_{1}, \mathrm{P}_{2}, \mathrm{P}_{3}$ e $\mathrm{P}_{4}$.

Os achados foram compatíveis aos encontrados pelo Instituto Mineiro de Gestão das Águas (IGAM) que identificou na localidade compreendida entre João Monlevade e Nova Era, à jusante da região das minas de ferro e entrada em área siderúrgica, presença dos coliformes termotolerantes até 9.208\% maior que o tolerável conforme CONAMA 357/2005. Tal situação mostrou a necessidade quanto à adoção de medidas contributivas nesse quesito, tais como, se evitar o lançamento de esgotos diretamente nos rios e a exposição de resíduos em lixões que são causas para o crescimento contínuo da poluição das águas (STENGER-KOVÁCS et al., 2013).

Observou-se que em $\mathrm{P}_{2}$ a concentração de OD (Gráfico 3) decaiu devido à introdução dos esgotos sanitários notadamente no período de estiagem (julho) quando a carga era alta e a vazão para diluição baixa e logo no início da temporada chuvosa (março) em função do carregamento de grandes quantidades de poluentes devido à lavagem das ruas, lixo e sedimentos (TUCCI \& MENDES, 2006). Destaca-se que foram alcançados Valor Inferior ao Mínimo (VIM) correspondente à $5 \mathrm{mg} \cdot \mathrm{L}^{-} \mathrm{O}_{2}$ para águas Classe 2 definido pelo CONAMA 357/05 em $\mathrm{P}_{3}$ (Gráfico $3)$. 


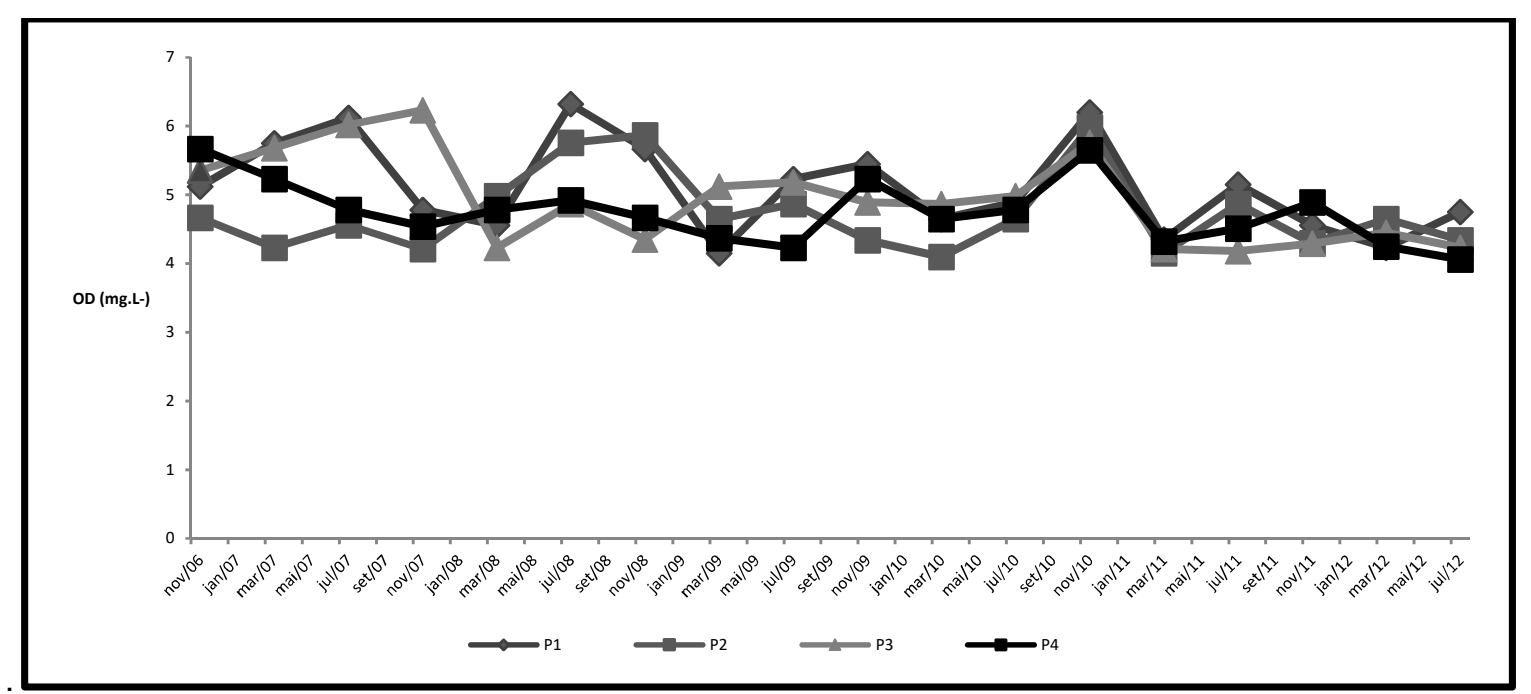

Gráfico 3: OD no Rio Piracicaba em $\mathrm{P}_{1}, \mathrm{P}_{2}, \mathrm{P}_{3}$ e $\mathrm{P}_{4}$.

Também foram identificados valores altos de $\mathrm{DBO}_{5,20}$ acima do VMP correspondente à 5 $\mathrm{mg} / \mathrm{L} \mathrm{O}_{2}$ para águas Classe 2 em todos os locais de coleta, sendo alcançados picos de 6,23mg. $\mathrm{L}^{-}$ $\mathrm{O}_{2}$ em $\mathrm{P}_{3}$ (Gráfico 4), explicitando à sujeição do corpo hídrico ao grande aporte de cargas orgânicas, principalmente esgotos domésticos e fontes difusas. Além disso, se constatou valores acima de 4,00mg.L'O $\mathrm{O}_{2}$ nos demais pontos de coleta denotando relação com o alto grau de industrialização favorecendo a redução do oxigênio dissolvido (Gráfico 3) o que pode provocar mortandades de peixes e eliminação de outros organismos aquáticos (NORIEGA et al., 2013).

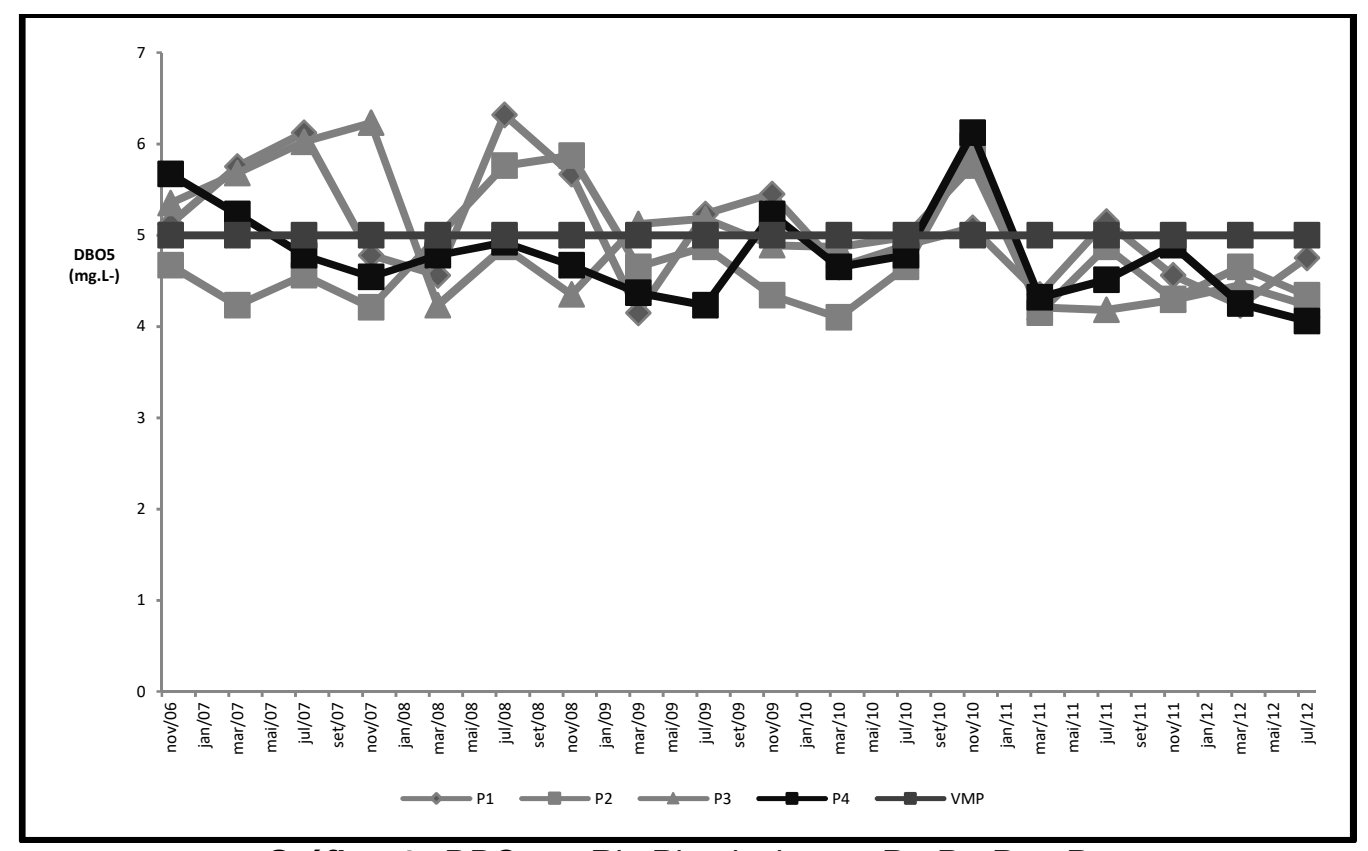

Gráfico 4: $\mathrm{DBO}_{5}$ no Rio Piracicaba em $\mathrm{P}_{1}, \mathrm{P}_{2}, \mathrm{P}_{3}$ e $\mathrm{P}_{4}$.

O potencial Hidrogeniônico $(\mathrm{pH})$ da BHRP oscilou entre 5,58 e 5,97 com distribuição praticamente homogênea indicando águas levemente ácidas. Os achados mostraram-se aumentados na estação das chuvas possivelmente relacionados com a intensa fotossíntese 
implementada pelas algas no reservatório da UHE- Sá Carvalho, dentre outras fontes antrópicas, em concordância com os achados de Silva et al. (2009) para UHE-Peti.

Outro risco se refere aos nutrientes, nitrogênio e fósforo fundamentais à cadeia alimentar por limitarem a produção de fitoplâncton. Todavia, a descarga de teores muito elevados nas águas superficiais e quando associados às boas condições de luminosidade entram em ciclo de enriquecimento redundando no fenômeno conhecido como eutrofização. A disfunção ambiental pode implicar na alteração do sabor, odor, turbidez, cor da água e redução do OD (Gráfico 3), provocando crescimento excessivo de plantas aquáticas, mortandade de espécimes aquáticos (inclusive as maiores, tais como, peixes) e comprometimento das condições mínimas para o lazer no corpo hídrico (SMITH \& SCHINDLER, 2009).

A precipitação pluviométrica, material alóctone (orgânico e inorgânico) e a fixação de nitrogênio pelo corpo hídrico são as principais fontes naturais de nitrogênio total $\mathrm{Na}$ área de amostragem os teores de $\mathrm{N}_{\text {Total }}$ (Gráfico 5) oscilaram entre o mínimo correspondente à 3,68mg. $\mathrm{L}^{-}$ em $\mathrm{P}_{1}$ (novembro/2006) ao teor máximo de 4,32mg.L' em $\mathrm{P}_{3}$ (novembro/20011) indicaram que a estações amostrais recebem contribuições diretas decorrentes das atividades antrópicas advindas da urbanização à jusante das localidades de coleta. Figueiredo et al. (2007) destacam que a agropecuária e o desmatamento aumentam a carga de nutrientes nos reservatórios que se distribuem ao longo do corpo aquático quando ocorre o transbordamento na estação chuvosa. Outro aspecto que ocorre se relaciona com o aumento exponencial da população de macrófitas aquáticas em função da oferta dos nutrientes (TUNDISI, 2006). Sendo assim, entende-se a contribuição da UHE- Sá Carvalho em relação ao incremento da carga $\mathrm{N}_{\text {Total }}$ na região de estudo.

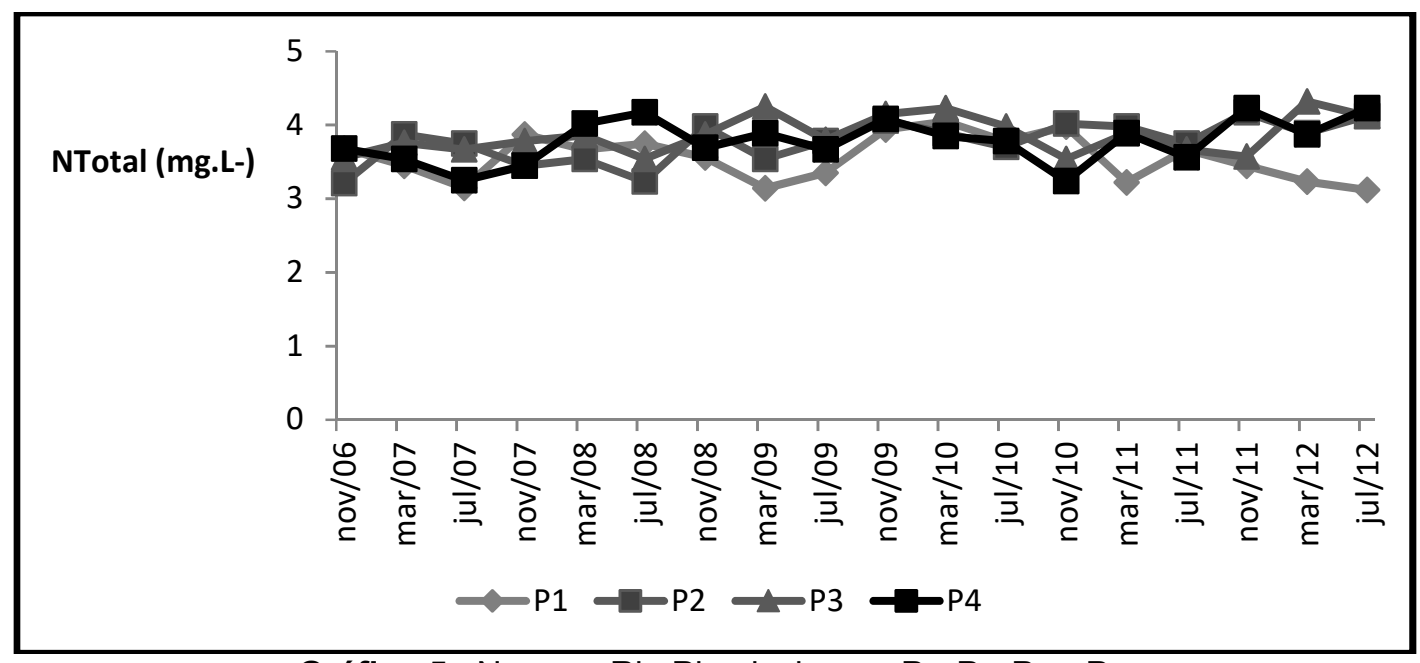

Gráfico 5: Ntotal no Rio Piracicaba em $\mathrm{P}_{1}, \mathrm{P}_{2}, \mathrm{P}_{3}$ e $\mathrm{P}_{4}$.

A contribuição da UHE-Sá Carvalho com o incremento teor de $P_{\text {total }}$ (Gráfico 6) ocorre em sua descarga na BHRP. Destaca-se que a água na entrada do reservatório apresenta também teores elevados de $\mathrm{P}_{\text {Total }} \mathrm{e} \mathrm{N}_{\text {Total. }}$. Constatou-se que à jusante da UHE-Sá Carvalho, as fontes potenciais de cargas orgânicas são esgotos domésticos que em diversos municípios são descarregados diretamente nos afluentes do reservatório. Por outro ângulo, ocorre o uso do solo 
para atividades agropecuárias, criação de suínos e aves. Essa realidade possivelmente favoreceu o acúmulo de nutrientes e matéria orgânica associando-se às características dendríticas do reservatório. Dados do monitoramento da CEMIG (2012) indicaram concentrações $N_{\text {Total }}$ e $P_{\text {Total }}$ respectivamente $393 \mu \mathrm{g} . \mathrm{L}^{-1}$ e $62,54 \mu \mathrm{g} \cdot \mathrm{L}^{-}$(amostras de fundo) inferindo relação com a carga de sedimentos carreados através da BHRP à montante da UHE-Sá Carvalho constituindo-se em fator contributivo no assoreamento do reservatório e exigindo limpezas periódicas a elevados custos (CARVALHO, 2008).

As amostras de água da BHRP apresentaram teores de $\mathrm{P}_{\text {Total }}$ (Gráfico 6) que extrapolaram o Valor Máximo Permitido (VMP) correspondente a $0,1 \mathrm{mg} \cdot \mathrm{L}^{-}$estabelecido pela Resolução CONAMA n³57/2005 em todas as localidades desse estudo. Destaca-se que os piores resultados foram detectados em $\mathrm{P}_{4}$ posicionado a $39 \mathrm{Km}$ da UHE-Sá Carvalho perdendo em proximidade para todas as demais localidades desse estudo.

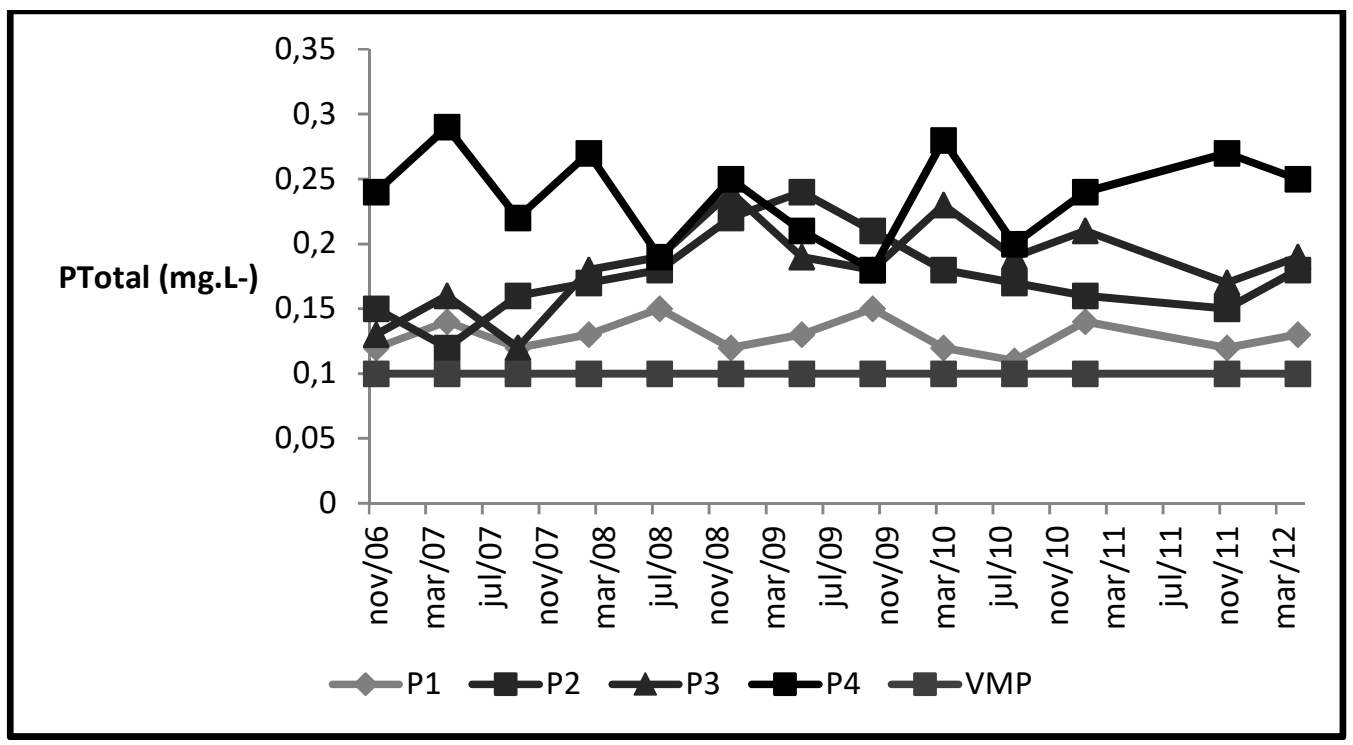

Figura 4: $\mathrm{P}_{\text {Total }}$ no Rio Piracicaba em $\mathrm{P}_{1}, \mathrm{P}_{2}, \mathrm{P}_{3}$ e $\mathrm{P}_{4}$.

Von Sperling e Von Sperling (2013) afirmam que $\mathrm{P}_{\text {Total }}$ encontrado na água, seja na forma iônica ou complexado, se apresenta como fosfato $\left(\mathrm{PO}_{4}^{-3}\right)$ sendo que as concentrações mais elevadas são geralmente associadas ao incremento da pluviometria em áreas com mata ripária degradado sendo esse também fator contributivo para os achados desse estudo. Além disso, os resultados encontrados na estação seca podem estar associados à dessorção do fósforo dos sedimentos, frente à redução da vazão e profundidade devido à estiagem (KÜTTER et al., 2014).

Para o recurso hídrico, os resíduos sólidos podem causar danos aos peixes e à vida aquática. Trata-se da sedimentação no leito dos rios destruindo organismos que fornecem alimentos, ou também danificar os leitos de desova de peixes. Os sólidos podem reter bactérias e resíduos orgânicos no fundo dos rios, promovendo decomposição anaeróbia. Além disso, podem apresentar altos teores de sais minerais, particularmente sulfato e cloreto, associando-se à 
tendência de corrosão em sistemas de distribuição, além de conferir sabor às águas (ANA, 2014). Tais condições oneram o tratamento da água visando a sua potabilização.

O regime de chuvas se torna componente ambiental preponderante também em relação ao Resíduo Total $\left(\mathrm{R}_{\text {Total }}\right)$, influenciando a qualidade de suas águas, seja pelo grau de diluição ou pelo transporte de nutrientes e/ou sedimentos (MICHEL et al., 2014). Tal situação foi identificada também para a BHRP nas localidades desse estudo sendo os valores mais elevados em $\mathrm{P}_{2}$ correspondente à $254 \mathrm{mg} \cdot \mathrm{L}^{-} \sigma= \pm 0,5602998$ e $\mathrm{P}_{4}$ sendo $324 \mathrm{mg} \cdot \mathrm{L}^{-} \sigma= \pm 0,7348356$. Destaca-se que o CONAMA 357/2005 determina que os resíduos sólidos objetáveis devam assumir a condição virtualmente ausente em águas Classe 1, 2 e 3.

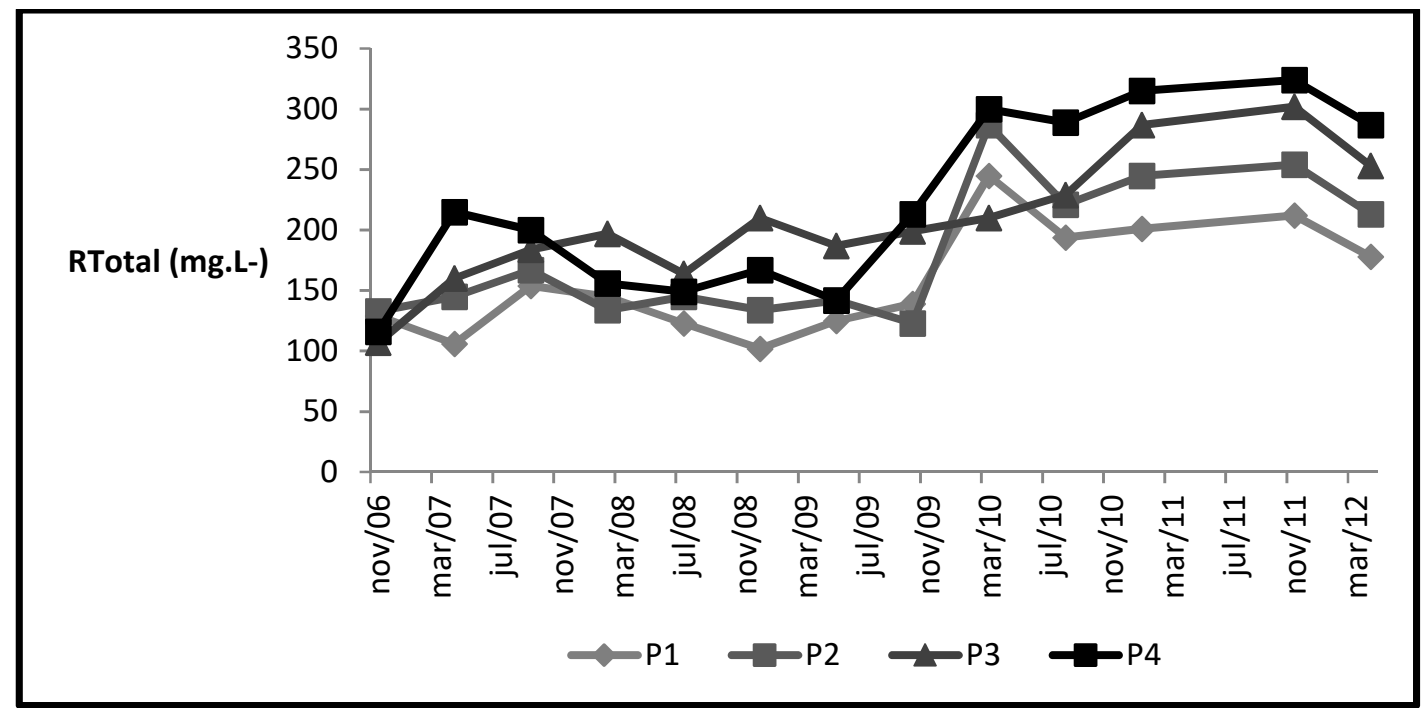

Gráfico 7: RTotal no Rio Piracicaba em $\mathrm{P}_{1}, \mathrm{P}_{2}, \mathrm{P}_{3}$ e $\mathrm{P}_{4}$.

No $R_{\text {Total }}$ se encontra incluso o material em suspensão, constituído de fração mineral ou inorgânica e outra orgânica. Um efeito importante se relaciona com a hidrodinâmica e a consequente redução de transporte de partículas decai ocorrendo a deposição do material em suspensão, diminuindo a profundidade do corpo d'água e relacionando-se com incremento da turbidez, salinidade e dureza da água (GÜNTZEL et al., 2012). A turbidez da água superficial se apresenta como um dos principais indicadores pertinentes às repercussões do uso e ocupaçao do solo em bacias hidrográficas, teores elevados dificultam a passagem da luz e conferem aparência turva ao corpo hídrico (NEVES et al., 2009).

$\mathrm{Na}$ região de estudo, os valores das taxas de turbidez (Gráfico 8) das amostragens realizadas explicitaram a interferência da sazonalidade e vazão da BHRP. Outro aspecto importante, a BHRP à jusante da UHE-Sá Carvalho encontra dificuldade para transportar por completo a carga em função das condições de assoreamento (CEMIG, 2014). Entretanto, o carreamento ainda que parcial afeta o ambiente lótico. Raposo et al. (2012) analisando a qualidade da água em localidades próximas à UHE - Lajeado relacionaram a turbidez do Ribeirão Taquaruçu com o reservatório notadamente nos meses com pluviometria aumentada. Curbelo et al. (2013) constataram que um alto nível de partículas suspensas no corpo aquático 
promove a difusão da solaridade e absorção do calor, o que aumenta a temperatura e disponibilidade para organismos aquáticos. As condições detectadas para a BHRP mostraram relação com a exploração econômica já que em sua saída após as mineradoras em trecho assoreado ainda apresenta contaminação por esgoto em diversos pontos. Tal condição ocorre de forma análoga ao longo da BHRD submetida à intensa remoção da mata ciliar e implicando na extinção das corredeiras além dos fundos cavernosos que eram o habitat de grande diversidade de espécimes ameaçadas de extinção, como o surubim e outras (COELHO et al., 2008).

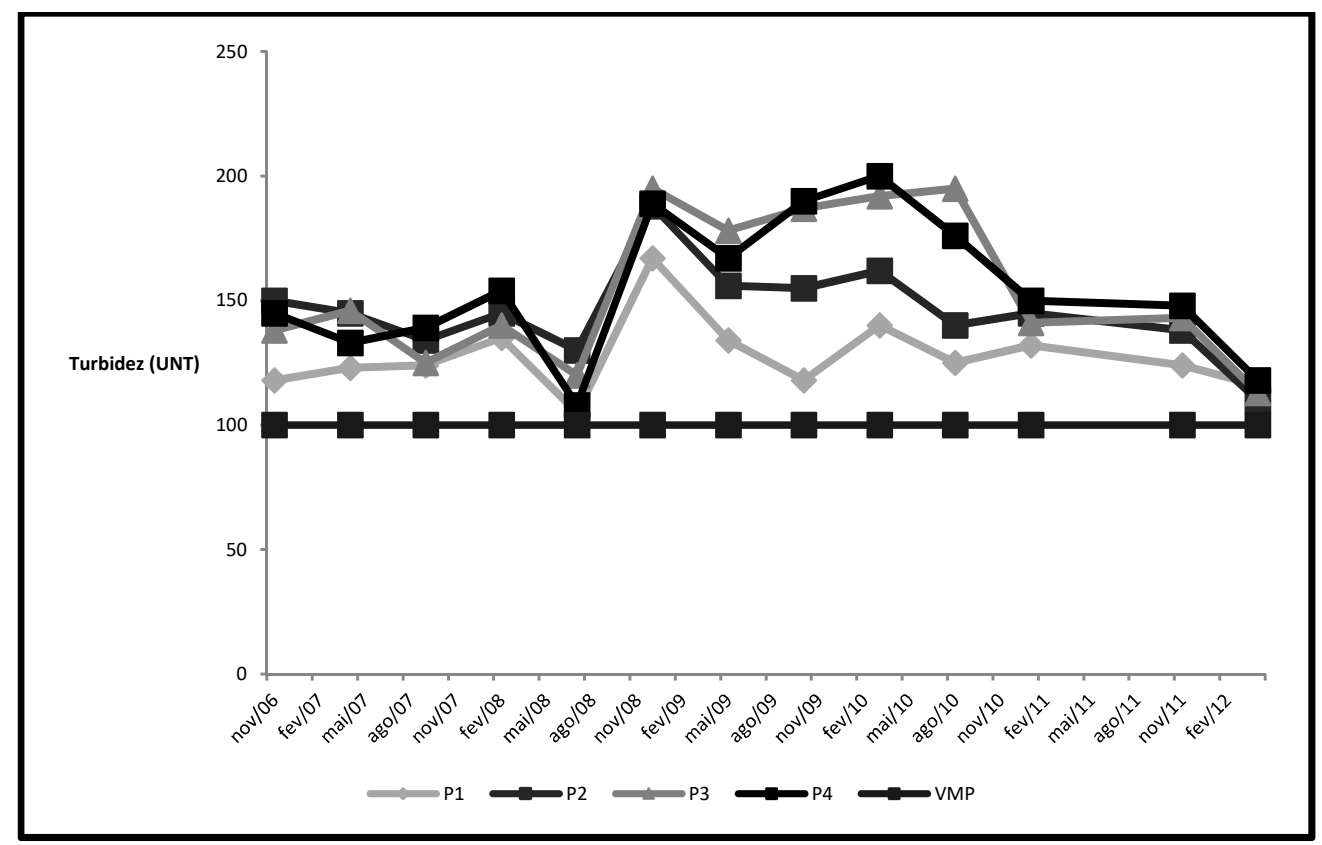

Gráfico 8: Turbidez no Rio Piracicaba em $\mathrm{P}_{1}, \mathrm{P}_{2}, \mathrm{P}_{3}$ e $\mathrm{P}_{4}$.

\section{CONCLUSÕES}

A qualidade da água na área de influência da UHE- Sá Carvalho se diferenciou entre as localidades abrangidas nesse estudo $\left(P_{1}, P_{2}, P_{3}\right.$ e $\left.P_{4}\right)$ apresentando correlação com o uso e ocupação do solo em função da carga de nutrientes inseridas na BHRP. Em $P_{1}$ se apurou menores valores de nitrogênio e fósforo quando comparados aos demais pontos de coleta, demonstrando menor nível de impacto por atividades agropastoris. Na estação amostral localizada em $\mathrm{P}_{4}$ foram alcançados os piores resultados em relação ao fósforo total e resíduo total. Tais parâmetros foram mais elevados nos períodos com elevação da precipitação pluviométrica, fato atribuído ao aporte de material alóctone carreado pelas chuvas do reservatório, dentre outras fontes antrópicas contributivas, aumentando seus teores e interferindo na dinâmica da biota aquática, notadamente da comunidade fito planctônica.

Além disso, constatou-se que o crescimento urbano interfere na qualidade da água da BHRP sendo que as localidades nos municípios de Coronel Fabriciano e Ipatinga apresentaram os piores valores de IQA. Destaca-se que os mesmos estavam localizados em área urbanizada, sendo identificada no município de Coronel Fabriciano a descarga de efluentes domésticos sem 
tratamento. Finalizando, para a proteção dos recursos hídricos se faz necessário o monitoramento hidrológico das sub-bacias, tal como a BHRP que afeta a dinâmica ambiental da BHRD, essa ação pode atuar como referência para o delineamento das medidas mitigadoras para outras bacias igualmente impactadas.

\section{REFERÊNCIAS}

ALVES, M. C.; SUZUKI, L. G. A. S.; SUZUKI, L. E. A. S.. Densidade do solo e infiltração de água como indicadores da qualidade física de um Latossolo Vermelho distrófico em recuperação. Rev. Bras. Ciênc. Solo. v.31, n.4, p.617-625, 2007.

APHA; AWWA; WEF. Standard methods for the examination of water and wastewater. 21 ed. Washington: American Public Health Association, 2005.

APRILE, F.; DARWICH, A. J.; MERA, P. A.; ROBERTSON, B. A.; MARSHALL, B. G.; SIQUEIRA, G. W.. On the occurrence of cyanobacteria in the madeira river in the Brazilian amazon. Agriculture \& Health Sciences. v.2, p.125-133, 2013

CACHIONI, M.; BRESSAN, A.; AMALFI, R. A.. Piracicaba em traços e cores. 1 ed. Piracicaba: IPPLAP, 2012.

CARVALHO, N. O.. Hidrossedimentologia Prática. Rio de Janeiro: Interciência, 2008.

CURBELO, F. D. S. ; GARNICA, A. I. C. ; BARROS NETO, E. L.. Salinity effect in cloud point phenomena by nonionic surfactants used in enhanced oil recovery tests. Petroleum Science and Technology, v.31, p. 1544-1552, 2013.

FRANKLIN, E.; FRANKLIN, E. ; DE MORAES, J.; MAGNUSSON, W. E.; DE SOUZA, J. L. P.; PEQUENO, P. A. C. L.; MAGNUSSON, W. E.; DE MORAIS, J. W.. Corrigendum to -Geographic position of sample grid but not the removal of uncommon species affect multivariate analyses of diverse assemblages. Ecological Indicators. v.36, p.745, 2014.

FURTADO, A. T.; SCANDIFFIO, M. I. G.. The Brazilian sugarcane innovation system. Energy Policy. v.39, p.156-166, 2010.

Güntzel, A. M.; MELO, I. K. M.; ROCHE, K. F.; SILVA, V. F. B.; POMPIANI, P. G.. Cladocerans from gut contents of fishes associated to macrophytes from Taquari River Basin, MS, Brazil. Acta Limnologica Brasiliensia, v.24, p.97-102, 2012.

KÜTTER, V. T.; WALLNER-KERSANACH, M.; SELLA, S. M.; ALBUQUERQUE, A. L, S.; KNOPPERS, B. A.; SILVA-FILHO, E. V.. Carbon, nitrogen, and phosphorus stoichiometry of plankton and the nutrient regime in Cabo Frio Bay, SE Brazil. Environmental Monitoring and Assessment (Print). v.186, p.559-573, 2014.

MACHADO, K. S.; FROEHNER, S.; SÁNEZ, J.; FIGUEIRA, R.; C. L.; FERREIRA, P. A. L.. Assessment of historical fecal contamination in Curitiba, Brazil, in the last $400 y$ years using fecal sterols. Science of the Total Environment. v.493, p.1065-1072, 2014.

MICHEL, G. P.; KOBIYAMA, M.; GOERL, R. F.. Comparative analysis of SHALSTAB and SINMAP for landslide susceptibility mapping in the Cunha River basin, southern Brazil. Journal of Soils and Sediments (Print), v.14, p.1266-1277, 2014.

NEVES, S. M. A. S.; CASARIN, R.; NEVES, R. J.. Implicações do uso da terra na qualidade das águas dos cursos fluviais da bacia hidrográfica do rio Paraguai-Jauquara (MT). In: SIMPÓSIO DE GEOTECNOLOGIAS NO PANTANAL. 2. Anais. Campinas: Embrapa/Inpe, 2009.

NORIEGA, C. D.; SANTIAGO, M. F.; FACANHA, P.; CUNHA, M. G. G.; SILVA, R. A.; FLORES MONTES, M.J.; MUNIZ, K.; ARAÚJO FILHO, M. C.; LEÇA, E. E.; LEITÃO, S. N.. The instantaneous transport of 
inorganic and organic material in a highly polluted tropical estuary. Marine and Freshwater Research, $v$. 64, p.562-572, 2013.

PEREIRA, P. R. A.; BARRAZA LARIOS, M. R.; SARTORI, M. V.; ALMEIDA, M. R. H.; TOLEDO, P. C. T.; COSTA, A. C.. Sistema de Remediação por Bombeamento e Tratamento em águas Subterrâneas Contaminadas. Interciência e Sociedade, v.1, p.137-147, 2011.

PERESIN, D.; TORGAN, L. C.; SCHULZ, U.; CROSSETTI, L. O.. Structure of potamoplankton along a gradient of preservation of riparian vegetation in subtropical streams. Academia Brasileira de Ciências (Impresso). v.86, p.841-853, 2014.

PIZELLA, D. G.; SOUZA, M. P.. Brazilian gmo regulation: does it have an environmental approach?. Journal of Environmental Assessment Policy and Management, v.14, 2012.

RAPOSO, A. A.; BARROS, L. F. P.; MAGALHÃES Jr, A. P.. O uso de taxas de turbidez da bacia do alto Rio das Velhas Quadrilátero Ferríferi/MG como indicar de pressões humanas e erosão acelerada. Revista Geografria (UFPE). v.1, p.31-45, 2012.

RODRIGUES, D. B. B.; OLIVEIRA, P. T. S.; ALVES SOBRINHO, T.; MENDIONDO, E. M.. Hydrological benefits in the context of Brazilian environmental services program. Environment, Development and Sustainability, v.1, p.1-12, 2012.

SILVA, A. P. S.; DIAS, H. C. T.; BASTOS, R. H. X.; SILVA, E.. Qualidade da Água do Reservatório da Usina Hidrelétrica (UHE) de Peti, Minas Gerais. Revista Árvore. Viçosa, v.33, n.6, 2009.

SILVA, D. C.; BELATO, M. N. ; SILVA, R. J. . comparison between current technologies for the best choice of thermoelectric plant with coal or uranium. Journal of Energy and Power Engineering, v.7, p.1719-1728, 2013.

SMITH, V. H.; SCHINDLER, D. W.. Eutrophication science: where do we go from here? Trends in Ecology and Evolution. v.24, p.201-207, 2009.

STENGER-KOVÁCS, C.; LENGYEL, E.; CROSSETTI, L. O.; ÜVEGES, V.; PADISAK, J.. Diatom ecological guilds as indicators of temporally changing stressors and disturbances in the small Torna-stream, Hungary. Ecological Indicators, v.24, p.138-147, 2013.

TUNDISI, J... Indicadores da qualidade da bacia hidrográfica para gestão integrada dos recursos hídricos. Estudo de caso: Bacia hidrográfica do Médio Tocantins. Tesis (Doctoral) - La Universidade Federal de São Carlos, PPGERN, 2006

TUCCI, C. E. M.; MENDES, C. A.. Avaliação Integrada de Bacia Hidrográfica, Instituto de Meio Ambiente e dos Recursos Naturais Renováveis. Brasília: Ministério do Meio Ambiente, 2006.

VON SPERLING, M.; VON SPERLING, E.. Challenges for bathing in rivers in terms of compliance with coliform standards. Case study in a large urbanized basin (das Velhas River, Brazil). Water Science and Technology. v.67, p.2534-2542, 2013.

ZIMMERMANN, C. M.; GUIMARAES, O. M.; ZAMORA, P. P.. Avaliação da qualidade do corpo hídrico do rio Tibagi na região de Ponta Grossa utilizando análise de componentes principais (PCA). Química Nova (Online), v.1, n.2, 2008. 